\title{
Familial isolated hypoparathyroidism
}

INSERM

\section{Source}

INSERM. (1999). Orphanet: an online rare disease and orphan drug data base. Familial isolated hypoparathyroidism. ORPHA:2238

Familial isolated hypoparathyroidism $(\mathrm{FIH})$ is a rare heterogeneous group of metabolic disorders characterized by abnormal calcium metabolism due to deficient secretion of parathormone (PTH), without other endocrine disorders or developmental defects. 